\title{
Considering the importance of metaphors for marine conservation ${ }^{\text {is }}$
}

\author{
Alasdair Neilson \\ The University of Edinburgh, Chrystal Macmillan Building, George Square, Edinburgh EH8 9DL, United Kingdom
}

\section{A R T I C L E I N F O}

\section{Keywords:}

Language

Marine conservation

Public perception research

\begin{abstract}
A B S T R A C T
This paper seeks to highlight the importance of metaphors for marine conservation and policy. It argues that the manner in which the oceans are perceived, often as an alien landscape, can limit the way language is utilised in marine conservation efforts. This limitation can produce unhelpful environmental metaphors that, instead of acting as catalysts for action, produce negative and reactionary responses. It illustrates this point through the example of what has become known as the 'Great Pacific Garbage Patch.' It postulates that if there is a disconnect between the many complex environmental issues facing the world's oceans and the way they are perceived, then more focus should be placed on developing pre-determined culturally embedded metaphors, which can conjure relatable imagery, but that are also rooted in scientific evidence. It recommends that, in an extension to existing public perception research (PPR) on how different communities value the ocean environment, there is room for shared metaphors of the oceanic environment to be developed that can help raise awareness within a particular cultural setting.
\end{abstract}

\section{Introduction}

Language has always played a significant role in the environmental movement, acting as a primary medium through which complex environmental issues are delivered to a wider public. Its influence can be profound [1,2]. There exists a good body of literature on the role of language concerning environmental and ethical issues, such as climate change, genetically modified crops, energy consumption, as well as the use of the natural capital metaphor [3-6], but little on the role of language in marine conservation.

There is, however, a growing body of literature on the study of public perception of the oceanic environment, which has come from the growth in what is known as Public Perception Research (PPR) [7-11]. Perception here is understood as an "umbrella term, which includes components such as knowledge, interest, social values, attitudes or behaviours" [11 p. 62]. Seeing as language plays a key role in shaping, attitudes, values and behaviours, it is surprising that more studies have not focused on the use of language within marine conservation.

Metaphors in particular, like that of Rachel Carson's Silent Spring, have proven to be powerful devices for capturing the public's imagination. Not only does Silent Spring contain metaphors throughout, it is itself a metaphor. As Burke states a "metaphor...can be a name-Silent Spring—or an explanation of a condition, a "silent spring" [12 p. 26]. Indeed, Nerlich calls Silent Spring "a counterfactual blend and auditory metaphor that represents the anti-climax following failed expectations and dashed hopes and cancels the tacit assumption that spring should be full of life, hope and joyful sounds" [13 p. 118]. Although Silent Spring had an astonishing reach, the metaphor was most effective in Western cultures, where silence has always maintained a menacing, threatening aura, being associated with death itself [13]. Birdsong, on the other hand, the dawn chorus, signals renewal, the onset of spring and the beginning of a new day.

Besides the broader cultural 'figurative extensions,' the power of Carson's Silent Spring metaphor in raising awareness of the effect of DDT also stemmed from its simple and relatable nature; it was a visual and audible metaphor for the otherwise silent process of pollution, and its emotive brilliance was such that it helped start a whole movement [14]. It was the fear of losing a noise and sight so ingrained into everyday human culture that became the catalyst for action. As Patton [15] states, where the ocean is concerned, the maxim of the great naturalist, Aldo Leopold rings especially true: "we can be ethical only in relation to something we see, feel, understand, love, or otherwise have faith in" [16 p. 251].

Through the conjuring of contextual imagery, drawn from concerns of what has happened as well what could happen, environmental metaphors, like silent spring, are as much cognitive as purely linguistic: "The function of metaphors...is...not just a descriptive one, they do not merely represent fact or fictions...they have a performative, and therefore political and ethical, force" [17 p. 9]. In this way, the power of the metaphor lies in their ability not only to shape perspectives of the

\footnotetext{
This article is based on a paper delivered at the Royal Geographical Society's International Conference, August 2016 and an essay published in Earthlines, March 2017, of which the author holds complete copyright.

E-mail address: aneilson@ed.ac.uk.
} 
environment, to raise awareness of a particular conservation issue, but also to act as a conduit for broader action. Indeed, recent studies have shown how metaphors can "powerfully influence cognition...increasing the accessibility of metaphor-related thoughts and eliciting metaphorcongruent behaviours" [18 p. 5].

To this end, how metaphors are used in environmental campaigns, conservation efforts, and by both policymakers and academics alike should not be taken lightly. This paper seeks to highlight the importance of metaphors for marine conservation and policy. Firstly, this paper will argue that there can be a problem with perception when it comes to conceptualising issues effecting the marine environment. Through the example of the 'Great Pacific Garbage Patch' it illustrates that this perception problem can produce unhelpful metaphors that fail to distil the actualities and complexities of marine environmental issues to the wider public. It will then set out how metaphors can be used in a more effective manner, arguing that an approach that is embedded in both socio-cultural values and scientific research is needed. This paper is not arguing that the use of metaphors are a panacea. Rather that if they are constructed with care and meet the requirements set out in this paper they could be effective in a number of policy areas, such as increasing engagement with citizen science programmes, communicating the importance of local marine management projects and explaining complex oceanic issues to the wider public and thereby helping to bridge the perception gap.

\section{The problem of perception}

"We are already beginning to learn that what the ocean has to offer extends beyond the limits of our imaginations."

Francis Minot [19 p. 44]

The then-Director of the Marine and Fisheries Engineering Research Institute, Francis Minot, made this prophetic statement in his aptly entitled book The Inexhaustible Sea, in which he detailed "the exciting story of the sea and its endless resources" [20 p. 12]. Replace the words "sea" and "ocean" with that of the "the West," and such statements could have easily been made by early American prospectors as they gazed westward across the seemingly endless, pristine landscape and its untapped resources [21]. Minot's sentiment echoed the zoologist and anatomist, Thomas H. Huxley ('Darwin's Bull Dog'), in his assertion that "probably all the great sea-fisheries are inexhaustible; that is to say that nothing we do seriously affects the number of fish" [22 p. 19]. Yet, as with any conceptualisation of a resource (be it deemed "natural" or otherwise) as an unexploited frontier, endless in bounty, Minot, and Huxley before him, were as mistaken in their prophecy as the prospectors.

Such statements regarding the unbounded nature of the oceans are, however, far from unique. Rachel Carson, the peerless chronicler of environmental degradation, proclaimed, "man cannot control, or change the oceans as, in his brief tenancy of earth he has subdued and plundered the continents" [23 p. 10]. Carson's statement was, in part, meant to evoke a reverence for the ocean realm, juxtaposed with what she saw as humanity's Promethean hubris in its exploitation of the natural world. It also, however, served to illustrate the belief that the fundamental composition of the oceans, in comparison to that of the land, cannot be controlled or altered: "deeply rooted in human culture is the attitude that the ocean is so vast, so resilient, it shouldn't matter how much we take out of - or put into - it" [24 p. 2-3].

As Carson rightly pointed out, during humanity's brief tenancy on earth, humans have fundamentally altered the characteristics of the land; urbanisation and the development of industrial agriculture, and the loss of biodiversity that such changes signalled, have brought enormous changes to forest, marshland and plain [25]. The oceanic form, with its liquidity and consistent surface complexion, hides the fact that the oceans are also industrial landscapes [26]. Indeed, technological advances, coupled with our growing need for energy, food and other resources, have seen oceans going through what Wright [27 p. 77] calls an "unprecedented period of industrialisation." Of course, it is all too well known that oceans are not a realm of boundless resources - the collapse of the Atlantic cod population in the early 1990s made this abundantly clear [28]. Nevertheless, the multifaceted complexity of the environmental problems facing the oceans today, coupled with the ocean's alien form and the fact that many of these environmental challenges cannot be rendered in a visual form, means that public perception can still be a problem [29-31]. As the environmental philosopher, Clark Wolf states [15 p. 6]:

"When we enter a marine environment - often importing with us a compressed version of our own non-marine environment - we may feel instead like alien, foreign visitors. For this reason, it is easier to generate public concern about deforestation in the Rockies."

This perception perpetuates oceanic degradation, as it becomes harder to comprehend the complex environmental issues the marine environment currently faces. This is not to say that this problem of perception is ubiquitous, as such a statement would be misleading. More that distilling these complex issues into more effective narratives for different audiences can be an especially tricky endeavour, as the imagery utilised is often limited. Section 2.1 provides a short example of how marine pollution can, unhelpfully, be characterised through clumsy metaphorical language.

\subsection{Texas, deserts, and the great pacific garbage patch}

Oceanic pollution is an umbrella term that covers a wide range of diverse environmental problems, such as agricultural runoff, industrial and municipal waste, and noise pollution [32]. The majority of the chemicals and particles that end up in the oceans originate from land and find their way into oceans' complex food chains [32]. Drawing on the results of the world's first survey of toxic contamination in marine mammals, Ferber illustrated how these pollutants are amassing in apex ocean predators, such as sperm whales [33]. A cocktail of human-made, land-originated pollutants is slowly moving around the world's oceans with, as Ferber states, "relative impunity" [33]. Indeed, in February 2017, researchers at Newcastle University published results showing that human-made pollutants are evident at the bottom the deepest ocean trenches on earth [34].

In recent years, several prominent environmental campaigns have emerged focusing on the issue of oceanic pollution and specifically the problem of plastic pollution. In the US, the majority of these campaigns focused their attention on what has been dubbed the 'Great Pacific Garbage Patch' or 'Eastern Garbage Patch,' a concentration of pelagic plastic particles and other debris caught up in the North Pacific Gyre. Greenpeace's (n.d.) website states: "The "Trash Vortex", also known as the "Eastern Garbage Patch", is an area equivalent in size to Texas, or Turkey, or Afghanistan, that slowly rotates our rubbish in a neverending rotation" [35]. Numerous media outlets [36-38] utilised the garbage patch metaphor to describe the nature of this pollution and the analogy of Texas to describe its size; pictures of floating plastic bags, bottles and other garbage often accompanied these stories. However, the majority of the pollution affecting the gyre is not an island of trash, but rather photo-degraded plastics and other pollutants [39].

Worryingly, this disconnect between the language utilised by campaigns and the actuality of the pollution in the North Pacific Gyre has served to foster counterproductive media coverage. Some saw the fact that you could not see this 'island of trash' twice the size of Texas rendered in visual form, and that the images accompanying stories of the 'Great Pacific Garbage Patch' were actually of Manila Harbour, as demonstrative of an environmental community increasingly prone to hyperbolic statements [14]. Nerlich [13] rightfully states that "metaphors can be used by experts and the media to shape visions of the past and/or the future in order to try to affect our social and political actions in the present." Yet, when the images that these metaphors conjure are 
disconnected from the reality of the situation, they can backfire leading to inaction instead of action. In 2016 The Telegraph [40] ran the headline 'Great Pacific Garbage Patch' is a myth,' stating that a survey of the area found just 1000 large objects in a survey of thousands of square miles. Indeed the word "trash" is equally unhelpful as Rathje and Murphy [41 p. 9] state "Trash refers specifically to discards that are at least theoretically "dry"-newspapers, boxes, cans, and so on," and thus does not seem comparable to the large amount of pollution affecting the North Pacific Gyre. It is also perhaps no coincidence that the three geographical regions used as allegories for the size of the garbage patch, were predominantly arid in nature (Turkey, Texas and Afghanistan). The metaphor of the desert landscape has often been used to describe the vastness of the oceans. Such a motif serves not only to separate humanity from the dynamic ecological process of the sea, but it has perpetuated a strange paradox that the ocean is at once a vast desert but also boundless in its resources, akin to Hugo Grotius' Mare Liberum, in which the Dutch philosopher treats the sea as if it lies "outside of human sociality and external to human law: a vast, boundless void" [42 p. 10].

As Ferber's study showed, the actual complexion of oceanic pollution is often far more insidious than the garbage patch metaphor would indicate. The poignant irony here is that the chemical most prevalent in the skin samples taken from sperm whales that Ferber tested was DDT [33], a chemical made infamous by Rachel Carson's Silent Spring. Finding metaphors and narrative devices, like that of Rachel Carson's Silent Spring, which distil complex environmental problems into relatively simple terms, is made more difficult by the complex nature of oceanic degradation. Issues such as whaling have dominated the collective consciousness of the environmental community, mainly because the industrial butchering of oceanic charismatic megafauna is a visceral and relatable image, much like the poaching of elephants, gorillas, and tigers: but what of ocean acidification or ocean noise pollution [14]? The cacophony caused by offshore oil rigs, navy sonar systems and the volume of ships that use the ocean, are causing major problems for those animals that navigate and communicate by clicks, whistles and pulses [14]. The metaphor of a 'Silent Sea' certainly does not fit here. Ultimately, such processes are happening far from humanity's sensory realm. Consequently, as Patton [15 p. 5] states the sea appears "unfamiliar - beyond us - and hence subject to the abuse of "the other" seen in human social contexts."

Any effort to increase awareness of oceanic degradation must have an appreciation of metaphor at its centre. It is a tightrope walk between making something more relatable and framing oceanic degradation in an accurate way. Metaphors have always played a key role in the environmental movement $[43,44]$ yet with much of oceanic degradation resisting image representation, they must play an increasingly important role in fostering change.

\section{Metaphor, PPR and policy}

\subsection{Social-cultural context}

In 'Politics and the English Language', Orwell [45] famously laments what he calls the "huge dump of worn-out metaphors." Metaphors, according to Orwell, have lost all evocative power because the socio-cultural context of their conception has become disconnected from their use, rendering any imagery that these metaphors used to conjure either meaningless or absent. Orwell cites "fishing in troubled waters" as an example of these disconnected linguistic devices, a nautical metaphor that arose out of the belief that rough seas would deliver the greatest catch [45]. Orwell's point is simple, but it remains profound; language is about imagery, and the power of metaphors, including environmental metaphors, stems from their ability to conjure imagery rooted in a particular socio-cultural context [46].

If, as Patton [15] states, the ocean suffers the abuse of the "other" then surely one of the aims of those involved in marine conservation is to make the oceanic environment more contextually and culturally relatable? As aforementioned, metaphors are intrinsically related to the environment in which they are produced, what Maturana and Varela call "structural coupling," that not only are metaphors always interacting with their discursive environment, they shape, and are shaped by, the (discursive) environment itself and "the sociocultural/economic circumstances of the time" [13 p. 136]. The search, therefore, should be for environmental metaphors of the marine environment that are rooted within a "local" context. In this way, not only will environmental metaphors have a greater likelihood of raising awareness of marine issues, but also this awareness will be translated into action and, consequently, change.

As Jefferson et al. [11 p. 64] rightly states, it is important to note the "heterogeneity in society's connection with the sea and to incorporate this into conservation engagement efforts." Although there exists a public awareness issue when it comes to issues facing the marine environment, this does not mean that societies do not value the oceans in a myriad of different ways [47-49]. Cultural relationships with the oceanic environment are often rooted in socio-historical pasts. The effectiveness of metaphors is reliant on being aware of these diverse histories, yet not confined by them. Orwell blamed worn-out metaphors on idleness, that the writer, unwilling to create his own imagery, twists metaphors out of their original meaning. Yet, it also true that metaphors can become redundant because the imagery they generate no longer has a significant societal connection. For example, Orwell [45] laments the misuse of the metaphorical 'hammer and the anvil,' stating that the way writers use it infers "the anvil gets the worst of it ... In real life it is always the anvil that breaks the hammer, never the other way about." Part of the reason for this confusion in imagery is that this metaphor was conceived during a time when the hammer and the anvil had far more cultural significance, after all, even in Orwell's time the number of professions that utilised a hammer and anvil was decreasing rapidly. If time has rendered the hammer and anvil a redundant metaphor, then the 'Great Pacific Garbage Patch' was redundant in its conception as the images it produced were disconnected from the actuality of the situation.

\subsection{Scientific rigour}

Metaphors are normally developed unconsciously and are often used implicitly without thought. Returning to Orwell, this is how metaphors can lose their meaning, as their use becomes based on habit the imagery they evoke is lost. Here this paper argues for a pre-determined approach to constructing metaphors, whereby, utilising PPR research, metaphors can be constructed that provide the most resonance with a particular audience. For oceanic issues, it is explanatory metaphors that are likely to have the most impact, as their use can help different audiences comprehend the diverse and often complex issues facing the marine environment [50]. Explanatory metaphors can be defined as:

"a research-driven...analogy that captures and distils a concept through reference to existing patterns of assumption and understanding...by using something that is familiar to people... as a source domain, and mapping some of its familiar features onto a target domain that is less familiar or well understood" [50 p. 10].

There are two important points to be made here: firstly, that the unfamiliar concept has to be mapped onto something that is familiar (to conjure the correct imagery) and, secondly, that the image conjured must be based on scientific knowledge, i.e. it must reflect the actuality of the situation, thereby reflecting scientific accuracy. It is, therefore, important that metaphorical language is not seen as unscientific. As Herrmann [51 p. 31] states the metaphor has historically been seen as a "threat" to scientific rigour: "this view is still reflected in academic writing conventions but has been opposed by research suggesting that metaphor is an indispensable part of natural language." There exists a 
false dichotomy between scientific thoroughness and metaphorical language. There are, however, fewer places where such language could be better utilised than in writing about the marine environment. For example, marine biologists have sought to compare the increasing levels of background noise in many parts of the world's oceans to a "continuous fog that is shrinking the sensory range of marine animals," or the pulses of navy sonar systems to the explosion of dynamite [52 $\mathrm{p}$. 18]. These comparisons resonate; fog, as it is a common weather phenomenon, and explosions of dynamite, as, through popular culture, we can conceptualise its effects both visually and audibly. Both of these examples are rooted in a shared, all be it broad, cultural knowledge, but they also reflect scientific truths. A 2014 study by the Frameworks Institute showed the effectiveness of the metaphor 'Osteoporosis of the Sea' to sum up the problem of ocean acidification and its effects on crustaceans to build and maintain their shells: "By giving people a concrete, relatable way to understand a complex and unfamiliar phenomenon - acidification - Osteoporosis gives people a strong grasp of the effects of acidification on certain types of shellfish, and the ocean system more generally" [50 p. 8]. Similarly, some marine scientist have used the metaphor of coral reefs are the lungs of the ocean to convey "the essential filtering functions of reef species and the intimate interconnectivity of marine ecosystems" [18 p. 1].

\subsection{The local level}

These examples reflect a broader shared understanding, but these ideas could be as equally effective on a more localised level by utilising specific cultural values and histories. Over the last decades far greater attention has been given to the role of local and indigenous knowledge in helping construct locally embedded marine conservation projects [53-56]. This increased focus on local coastal knowledge and its role in mitigating environmental problems has resulted in the creation of knowledge exchanges in marine and coastal policy. The Coastal Communities Alliance, Mwambao Coastal Community Network, the CircumArctic Coastal Communities Knowledge Network, UArctic Thematic Network and Mission Blue to name just a few, all focus on the importance of sharing local knowledge of the marine environment, both between different coastal communities and amongst diverse stakeholders. Although these networks have primarily focused on knowledge as a means of adaptation, they could also be used as a way to foster metaphors for the purpose of raising awareness about the problems facing the oceanic environment, to comprehend the problems of the ocean within a particular cultural context.

This could be especially helpful in raising awareness around local population levels and, what the fisheries biologist Daniel Pauly calls, shifting baseline syndrome. Here localised metaphorical accounts could act as a catalyst for awareness and change. Historical accounts are particularly useful in building a picture of past population baselines, and should not be dismissed [57]. British fishermen use to refer to cod as "gold" or as "their bread." Although it was this worth that lead to overfishing, such metaphors could illustrate the historic value, both in monetary and culturally symbolic terms, that cod had in their community and could help frame localised management efforts [58 p. 316]. The "gold" metaphor still rings true as gold is still understood to be a precious resource even if the value of cod is generally less well known.

The bedrock for the construction of these pre-determined, locally embedded metaphors must be research into local histories and sociocultural values of the seas. Indeed, in a recent paper Gee et al. [59] highlighted the importance of culturally significant areas for marine spatial planning (MSP). They highlight a significant gap in research when it comes to understanding the cultural values of coastal communities: "The ecological and economic evidence base for MSP tends to be relatively well developed. This cannot be said for socio-cultural values associated with the sea, understood here as mainly immaterial values placed on the environment by people" [59 p. 140]. The important point here is that culture is defined through non-material means. It is the immateriality that at once gives these values power, as their intangibility gives them temporal flexibility, but also make them tricky to pin down, study and draw upon for conservation purposes. As Gee et al. state, it is participation between the numerous coastal stakeholders where definitions of what cultural values are must take place. They highlight the following forms of information as a basis for shared values: descriptions of activities (fishing, hunting, gathering), accounts about specific events linked to place recounted in stories or myths, ritual observances and belief practices [59]. What is particularly striking about this list is how metaphors could potentially feature as a medium to express this information (describing practices, ritual observations) or as a part of the very cultural fabric itself (myths). Indeed, the study and application of metaphors for purposes of conservation could fit into almost all types of PPR. This is evident in Jefferson et al.'s framework for how PPR can be translated into action [11 p. 69]. Inspiration can be taken from Social Anthropology, which has a rich history of studying how "technical issues" are often understood in relation to broader cultural value and belief systems. As Leach et al. state central to this research has been the "exploration of local concepts, metaphors, and idioms, examining how these make sense in relation to their particular social and cultural setting" [60 p. 19].

\section{Conclusion}

The clumsy use of metaphors can cause unwanted media coverage. Since environmental issues are increasingly prone to partisan politics, this coverage is at best unhelpful, and at worst completely counterproductive to conservation efforts and subsequent policy and behaviour change. If the nature of what is being described through language is disconnected from the actuality of the situation then, not only will negative coverage persist, but broader action will not be catalysed. However, the policy outcomes of using metaphors effectively could be manifold. On a local level, they could help encourage engagement with local conservation or citizen science programmes, help to explain the importance of particular marine management projects, and help to bridge diffuse stakeholders. More broadly they could raise awareness of particular ocean issues that the public may find it hard to resonate with, and can thus be the catalyst for broader action. However, two broad criteria need to be met when constructing these metaphors:

- Firstly, the image conjured must be embedded in some shared cultural idea (it must be effective in raising awareness of helping to relate specific information around marine conservation)

- Secondly, they must be rooted in both scientific knowledge (i.e. the imagery conjured must reflect the actuality of the situation).

The research to both test the effectiveness of using metaphors to raise awareness of marine issues and to gather the necessary data on which to base said metaphors fits perfectly within the parameters of marine PPR. Indeed, with its cross-disciplinary toolkit and its engagement with both policymakers, practitioners and diverse audiences alike, make marine PPR best placed to carry this research forward.

The use of metaphor in marine conservation should on no account be seen as a panacea because panaceas rarely exist for tackling such complex environment issues. Rather, when used in a way that conjures a given image whilst remaining firmly based in rigorous scientific knowledge, they should be seen as an incredibly useful tool for bridging the perception gap, helping to raise awareness around some of the most pressing environmental issues.

\section{Acknowledgements}

I would like to thank the editors of Marine Policy for their feedback and Dr Emma McKinley and Dr Timothy Acott for asking me to contribute to this Special Issue. They have provided me with invaluable guidance and support 


\section{Conflicts of interest}

None.

\section{References}

[1] C.M. Raymond, G.G. Singh, K. Benessaiah, J.R. Bernhardt, J. Levine, H. Nelson, N.J. Turner, B. Norton, J. Tam, K.M.A. Chan, Ecosystem services and beyond: using multiple metaphors to understand human - Environment relationships, Bioscience 63 (2017) 536-546, http://dx.doi.org/10.1525/bio.2013.63.7.7.

[2] A. Steinbach, Metaphor and Visions of Home in Environmental Writing, Harvard Univ, Sustain, 2016〈https://green.harvard.edu/news/metaphor-and-visions-homeenvironmental-writing $\rangle$.

[3] B.R. Calel, Environmental policy and public opinion, Opticon 1826 (2010) 1-6.

[4] G. Cook, Genetically Modified Language: The Discourse of Arguments for GM Crops and Food, Routledge, London, 2004.

[5] A. Nadal, The natural capital metaphor and economic theory, real-world, Econ. Rev. (2016) 64-84.

[6] A. Neilson, The socio-political importance of blackouts in South Africa, Soc. Sp. (Przestrz. Społeczna) 13 (2017) 79-93.

[7] L. Williams, Public Attitudes Towards the Maritime Environment Around the Menai Strait \& Conwy Bay, Countryside Council for Wales, Cardiff, 2008.

[8] A. Corner, S. Capstick, N. Pidgeon, Public Perceptions of Ocean Acidification Summary Findings of Two Nationally Representative Surveys of the British Public, October, (n.d.), 2014, pp. 1-26.

[9] S. Gelcich, P. Buckley, J.K. Pinnegar, J. Chilvers, I. Lorenzoni, G. Terry, M. Guerrero, Public awareness, concerns, and priorities about anthropogenic impacts on marine environments, Proc. Natl. Acad. Sci. USA 111 (2014) 15042-15047, http://dx.doi.org/10.1073/pnas.1417344111.

[10] R.L. Jefferson, I. Bailey, D.A. Laffoley, J.P. Richards, M.J. Attrill, Public perceptions of the UK marine environment, Mar. Policy 43 (2014) 327-337, http://dx.doi.org/ 10.1016/j.marpol.2013.07.004.

[11] R. Jefferson, E. Mckinley, S. Capstick, S. Fletcher, H. Grif, M. Milanese, Understanding audiences: making public perceptions research matter to marine conservation, Ocean Coast. Manag. 115 (2015) 61-70, http://dx.doi.org/10.1016/ j.ocecoaman.2015.06.014.

[12] J.E. Burke, Silent Spring's, Thesis Submitt. to Fac. Virginia Polytech. Inst. State Univ. Partial Fulfillment Requir. Degree Master Sci. Sci. Technol. Soc, 2004.

[13] B. Nerlich, Breakthroughs and disasters: the politics and ethics of metaphor use in the media, in: H. Schmid, S. Handl, W. de Gruyte (Eds.), Cogn. Found. Linguist. Usage Patterns Empir. Stud. De Gruyter Mouton, Berlin, 2010.

[14] A. Neilson, Beneath the waves: perception and oceanic degradation, Earthlines 17 (2017) 21-25.

[15] K. Patton, The Sea Can Wash Away All Evils: Modern Marine Pollution and the Ancient Cathartic Ocean, Columbia University Press, New York, 2006.

[16] A. Leopold, A Sand Country Almanac and Other Sketches Here and There, Oxford University Press, Oxford, 1968.

[17] R. Elliott, Communicating Biological Sciences: Ethical and Metaphorical Dimensions, Routledge, London, 2016.

[18] J.P. Schuldt, K.A. Mccomas, S.E. Byrne, J.P. Schuldt, Communicating about ocean health: theoretical and practical considerations, Philos. Trans. R. Soc. B 371 (2016), http://dx.doi.org/10.1098/rstb.2015.0214.

[19] K. Bailey, Billion-Dollar Fish: The Untold Story of Alaska Pollock, University of Chicago Press, Chicago, 2013.

[20] R. Ellis, TheEmpty Ocean, Island Press, Washington, D.C, 2013.

[21] W.H. Katerberg, A Northern Vision: Frontiers and the West in the Canadian and American Imagination, 2011, 2017. http://dx.doi.org/dx.doi.org/10.1080/ 02722010309481366

[22] J. Baden, D. Noonan, Managing the Commons, Indiana University Press, Bloomington, 1998

[23] R. Carson, The Sea Around us, Oxford University Press, Oxford, 1951.

[24] S. Earle, The World Is Blue: How Our Fate and the Ocean's are One, Nationa Geographic Books, Washington, D.C, 2009.

[25] S. Hari, M. Khan, Urbanisation, Environmental Degradation and Quality of Life, Rawat Publications, Jaipur, 2016.

[26] H.D. Smith, The industrialisation of the world ocean, Ocean Coast. Manag. 43 (43) (2000) 11-28.

[27] G. Wright, Marine governance in an industrialised ocean: a case study of the emerging marine renewable energy industry, Mar. Policy 52 (2015) 77-84, http:// dx.doi.org/10.1016/j.marpol.2014.10.021.

[28] P.R. Sinclair, Sustainable development in Fisher- ies dependent regions? Reflections on Newfoundland cod fisheries, Sociol. Rnrdis. 36 (1996) 224-235.

[29] K. Chi, J. Euan, M. Luisa, Public perception of development issues: impact of water pollution on a small coastal community, Ocean Coast. Manag. 45 (2002) 405-420.

[30] B.S. Steel, C. Smith, L. Opsommer, S. Curiel, R. Warner-steel, Public ocean literacy in the United States, Ocean Coast, Manag 48 (2005) 97-114, http://dx.doi.org/10. 1016/j.ocecoaman.2005.01.002.

[31] S. Fletcher, J.S. Potts, C. Heeps, K. Pike, Public awareness of marine environmental issues in the UK, Mar. Policy 33 (2009) 370-375, http://dx.doi.org/10.1016/j. marpol.2008.08.004.
[32] B. Clark, Marine Pollution, Oxford University Press, Oxford, 2001.

[33] D. Ferber, Sperm whales bear testimony to ocean pollution, ScienceMag (2005), http://dx.doi.org/10.1126/science.309.5738.1166b.

[34] A.J. Jamieson, T. Malkocs, S.B. Piertney, T. Fujii, Z. Zhang, Bioaccumulation of persistent organic pollutants in the deepest ocean fauna, Nat. Ecol. Evol. 1 (2017) 51, http://dx.doi.org/10.1038/s41559-016-0051.

[35] The Trash Vortex, Greenpeace. (n.d.). 〈http://www.greenpeace.org/international/ en/campaigns/oceans/fit-for-the-future/pollution/trash-vortex/> (Accessed 9 June 2017)

[36] Giant Ocean-Trash Vortex Documented-A First, Natl. Geogr. 〈http://news nationalgeographic.com/news/2009/09/photogalleries/pacific-garbage-patchpictures/index.html $>$ (Accessed 9 June 2017).

[37] S. Farberrov, Amount of plastic in Texas-sized Great Pacific Garbage Patch has increased Hundredfold since the 1970s, Mail Online. 〈http://www.dailymail.co.uk/ news/article-2141911/Scientists-Amount-plastic-Texas-sized-Great-PacificGarbage-Patch-increased-HUNDREDFOLD-1970s.html>.

[38] Trash-mapping expedition sheds light on Great Pacific Garbage Patch, Guard. 〈https://www.theguardian.com/us-news/2015/aug/23/pacific-ocean-plastictrash-mapping-mission> (Accessed 9 June 2017), 2015.

[39] A.L. Andrady, Microplastics in the marine environment, Mar. Pollut. Bull. 62 (2011) 1596-1605, http://dx.doi.org/10.1016/j.marpolbul.2011.05.030.

[40] Great Pacific Garbage Patch is a myth, warn experts, as survey shows there is no'rubbish island, Telegr. 〈http://www.telegraph.co.uk/science/2016/10/05/ great-pacific-garbage-patch-is-a-myth-warn-experts-as-survey-sho $>$ (Accessed 9 June 2017).

[41] W. Rathje, C. Murph, Rubbish!: The Archaeology of Garbage, University of Arizona Press, Tucson, 2001.

[42] M. Samuelson, H. Zerriffi, Sea changes, dark Tides and littoral States: oceans and castlines in post-apartheid South African Narratives, Altern. Spec. Ed. 6 (2013) 9-28.

[43] R.J. Brulle, Environmental discourse and social movement organizations, Sociol. Inq. 66 (1996) 58-83.

[44] M. Lytle, The Gentle Subversive: Rachel Carson, Silent Spring, and the Rise of the Environmental Movemen, Oxford University Press, New York, 2007.

[45] G. Orwell, Polit. Engl. Lang. (1946) 1-13〈http://www.orwell.ru/library/essays/ politics/english/e_polit/>.

[46] T. Carver, J. Pikalo, Political Language and Metaphor: Interpreting and Changing the World, Routledge, London, 2008.

[47] E. Mckinley, S. Fletcher, Improving marine environmental health through marine citizenship: a call for debate, Mar. Policy 36 (2012) 839-843, http://dx.doi.org/10. 1016/j.marpol.2011.11.001.

[48] J. Urquhart, T. Acott, M. Zhao, Introduction: social and cultural impacts of marine fisheries, Mar. Policy 37 (2013) 1-2, http://dx.doi.org/10.1016/j.marpol.2012.04. 007.

[49] T. Acott, J. Urquhart, Sense of place and socio-cultural values in fishing communities along the English Channel, in: J. Urquhart, T. Acott, D. Symes, M. Zhao (Eds.), Soc. Issues Sustain. Fish. Manag. MARE Publ. Ser. 9 Springer, Netherlands, New York London, 2014, pp. 257-277, , http://dx.doi.org/10.1007/978-94-007-7911 2_14.

[50] A. Volmert, Getting to the Heart of the Matter: Using Metaphorical and Causal Explanation to Increase Public Understanding of Climate and Ocean Change, A Framework, 2014.

[51] J. Herrmann, Metaphor in Academic Discourse: Linguistic Forms, Conceptual Structures, Communicative Functions and Cognitive Representations, Amsterdam University, Amsterdam, 2013.

[52] M. Jasny, Sounding the depths II: the rising Toll of sonar, Shipp. Ind. Ocean Noise Mar. Life (2005), 〈https://www.nrdc.org/sites/default/files/sound.pdf〉.

[53] M. Gadgil, F. Berkes, C. Folke, Indigenous knowledge for Biodiversit conservation, Ambio 22 (1993) 151-156.

[54] J.M. Shackeroff, L.M. Campbell, Traditional ecological knowledge in conservation research: problems and prospects for their constructive engagement, Conserv. Soc 5 (2007) 343-360.

[55] R.K. Brook, S.M. Mclachlan, Trends and prospects for local knowledge in ecological and conservation research and monitoring 1C, Biodivers. Conserv. 17 (2008) 3501-3512, http://dx.doi.org/10.1007/s10531-008-9445-x.

[56] N.C. Ban, L. Eckert, M. Mcgreer, A. Frid, N.C. Ban, L. Eckert, M. Mcgreer, A. Frid, Indigenous knowledge as data for modern fishery management: a case study of Dungeness crab in Pacific Canada Indigenous knowledge as data for modern fishery management: a case study, Ecosyst. Heal. Sustain. 3 (2017), http://dx.doi.org/10. 1080/20964129.2017.1379887.

[57] J. Jackson, K. Alexander, E. Sala, Shifting Baselines: The Past and the Future of Ocean Fisheries, Island Press, Washington, D.C, 2012.

[58] H. Saberi, Cured, Smoked, and Fermented: Proceedings of the Oxford Symposium on Food and Cooking, 2010, Oxford Symposium, Oxford, 2011.

[59] K. Gee, A. Kannen, R. Adlam, C. Brooks, M. Chapman, R. Cormier, C. Fischer, S. Fletcher, M. Gubbins, R. Shucksmith, R. Shellock, Ocean \& coastal management identifying culturally signi fi cant areas for marine spatial planning, Ocean Coast. Manag. 136 (2017) 139-147, http://dx.doi.org/10.1016/j.ocecoaman.2016.11. 026.

[60] M. Leach, I. Scoones, B. Wynne, Science and Citizens: Globalization and the Challenge of Engagement, Zed Books Ltd, London, 2013. 